\title{
Health Communication, Knowledge, Perception and Behavioral Responses to COVID-19 Outbreak in Dessie, Kombolcha and Kemissie Towns, Amhara Region, Northeast Ethiopia: A Mixed-Method Study
}

\section{Zemen Mengesha Yalew (D) Yibeltal Asmamaw Yitayew (iD) ${ }^{2}$ Ebrahim Seid Mohammed ${ }^{3}$ Tesfaye Bezabih Gezihagne ${ }^{3}$ \\ 'Department of Comprehensive Nursing, College of Medicine and Health Science, Wollo University, Dessie, Ethiopia; 2Department of Pediatrics and Child Health Nursing, College of Medicine and Health Science, Wollo University, Dessie, Ethiopia; ${ }^{3}$ Department of Journalism and Communication, College of Social Sciences, Wollo University, Dessie, Ethiopia}

Correspondence: Yibeltal Asmamaw Yitayew

Email yibie.asmamaw2I@gmail.com
Background: Despite the efforts made to mitigate the spread of COVID-19 in Ethiopia, new cases continue to rise. Therefore, to overcome the devastating effects of the outbreak, health communication and the community's knowledge, perception, and behavioral responses towards COVID-19 should be assessed.

Methods: A community-based cross-sectional study design was conducted from June 15 to July 30, 2020, with 827 and 18 participants for the quantitative and qualitative study, respectively. The data were collected using ODK collect and exported to SPSS version 25 for analysis. Multivariate logistic regression was computed, and variables that had a significant association were interpreted at $\mathrm{p}<0.05$ with a $95 \%$ CI. Additionally, the qualitative data were collected using in-depth interview and then transcribed, translated, and analyzed using thematic content analysis.

Results: The majority (97.8\%) of respondents obtained information about COVID-19 through broadcast media, and $58.5 \%$ of the participants had good knowledge of COVID-19. Likewise, $51.3 \%, 60.9 \%, 73.8 \%, 35.1 \%$, and $74.2 \%$ of participants had high perceived susceptibility, severity, benefit, barrier, and self-efficacy to COVID-19, respectively. Additionally, $54.3 \%$ of respondents had good behavioral responses to COVID-19. Kombolcha town residents (AOR: 4.32 , 95\% CI, 2.02-9.2), aged from 25 to 34, and 35 to 44 years old (AOR: 2.62, 95\% CI, $1.37-$ 5.0), and (AOR: $2.23,95 \% \mathrm{CI}, 1.11-4.46$ ), respectively, secondary or above education (AOR: 2.38, 95\% CI, 1.17-4.86), good knowledge of COVID-19 (AOR: 2.07, 95\% CI, 1.42-3.02), high perceived self-efficacy (AOR: 4.90, 95\% CI, 3.10-7.75), and low perceived barriers (AOR: 3.17, 95\% CI, 2.12-4.74) to COVID-19 preventive measures were significantly associated with the behavioral responses to COVID-19.

Conclusion: In this study, the behavioral responses to COVID-19 were relatively low. Therefore, continuous awareness creation is needed to scale up the community's knowledge and perceived self-efficacy. Furthermore, the general public, especially young people, should follow the government's COVID-19 prevention and control rules and regulations.

Keywords: COVID-19, health communication, knowledge, perception, behavioral response, Ethiopia

\section{Introduction}

The novel coronavirus (COVID-19) was identified from China in December 2019 among a cluster of patients presented with an unidentified form of viral pneumonia. ${ }^{1}$ Following the identification of cases in countries outside China, the 
World Health Organization (WHO) officially declared COVID-19 as pandemic. ${ }^{2}$ As of February 15, there were nearly 109,572,064 infected individuals and 2,415,427 deaths worldwide. Similarly, in Ethiopia, 146,492 total infected cases and 2,194 deaths were recorded. ${ }^{3,4}$

The novel coronavirus disease (COVID-19) has a devastating effect on global health and economy. ${ }^{5}$ The health and economic impact of the COVID-19 pandemic has been felt worldwide. In particular, the virus could have a devastating effect on developing nations, including Africa. ${ }^{6}$ Healthcare systems in this region are inadequate, owing to a lack of equipment and funding, insufficient healthcare worker training, and inefficient data transmission. ${ }^{7}$ Likewise, the health system and infrastructure in Ethiopia are weak. The latest readiness assessments from the WHO indicated that there was an extremely limited intensive-care unit capacity for the treatment of severe COVID-19 cases. ${ }^{8}$

The World Health Organization (WHO) has made several recommendations to limit the spread of COVID-19 in the community. These include hand hygiene, maintaining social distance, avoiding crowded places, avoiding touching the eyes, nose, and mouth, maintaining good respiratory hygiene, staying at home, seeking medical attention if you have symptoms, and staying up to date on trusted information. ${ }^{9}$ Similarly, the Ethiopian ministry of health and Ethiopian public health institute introduced public health measures to prevent and control the COVID-19 outbreak. $^{10}$

Health communication plays an important role in health promotion and disease prevention because it increases knowledge, influence perception, and reinforce behavioral changes. ${ }^{11,12}$ During the COVID-19 pandemic crisis, timely, accurate, and credible health communication is a key factor in saving lives. Reliable and well-developed health communication is beneficial in educating new strategies, easing uncertainty management, and reinforcing the implementation of COVID-19 protective measures. $^{13,14}$ Public health communication will be essential to ensure that people understand the risks of COVID-19 and follow authorities' recommendations to protect themselves and the community. ${ }^{15}$

Various health education and psychological models indicate that perception is a key predictor to behavioral response. People who perceive a higher level of risk are more likely to implement preventive measures. ${ }^{16}$ In Ethiopia, there is a high level of behavioral non-adherence, lack of protective equipment, myths, false surety, and low adaptations to standard precautions. These will result in a higher likelihood of ignorance of protective measures and reduce the capacity to control the virus. ${ }^{17}$

Despite various efforts made to mitigate the spread of COVID-19 in Ethiopia, new cases continue to rise. Additionally, there is a significant gap in the implementation of COVID-19 prevention measures among the public. ${ }^{18}$ Therefore, to better control and overcome the devastating effects of COVID-19, the health communication and community's knowledge, perception, and behavioral responses to COVID-19 outbreak should be assessed.

\section{Methods and Materials}

\section{Study Design, Setting and Period}

A community-based mixed-method cross-sectional study was conducted among the residents of Dessie, Kombolcha, and Kemissie towns from June 15-July 30, 2020. Dessie, Kombolcha, and Kemissie towns are located 401, 378.6, and $326.2 \mathrm{~km}$ away from Addis Ababa, the capital city of Ethiopia, respectively. According to the 2019 Central Statistics Agency-Ethiopia population projection report, Dessie, Kombolcha, and Kemissie towns had total population of 268,931, 144,946, and 37,642, respectively. ${ }^{19}$ According to the towns' administration office, the towns of Dessie, Kombolcha, and Kemissie have an estimated $57,687,34,210$, and 10,300 households, respectively.

\section{Population}

\section{Source Population}

All residents of Dessie, Kombolcha and Kemissie towns.

\section{Study Population}

Randomly selected household heads (household member aged $\geq 18$ years) who live in Dessie, Kombolcha, and Kemissie towns.

\section{Sample Size Determination and Sampling Technique}

The sample size was calculated using a single population proportion formula by considering $50 \%$ good behavioral responses to COVID-19 to obtain the largest sample size, with a $95 \% \mathrm{CI}$ and $5 \%$ marginal error.

The sample size was calculated using the following formula:

$$
\begin{aligned}
& \mathrm{Ni}=(\mathrm{Z} \mathrm{a} / 2)^{2} \times \mathrm{p}(1-\mathrm{p}) / \mathrm{W}^{2} \\
& \mathrm{Ni}=(1.96)^{2} \times(0.5) \times(0.5) /(0.0025)=384 \\
& \text { where: } \\
& \mathrm{Ni}=\text { Initial sample size } \\
& \mathrm{a}=\text { Confidence interval }
\end{aligned}
$$


$\mathrm{p}=$ Prevalence of good behavioral responses

$\mathrm{W}=$ margin of error

By considering a $10 \%$ non-response rate, the sample size was 422 households. However, due to the use of a multistage sampling procedure, the final sample size was 844 .

Regarding the sampling procedure, four kebeles (the smallest administration unit) from each town were selected randomly, and the study households were selected by using a systematic random sampling technique $(k \approx 40)$ (Figure 1). After selection, the household head (father or mother) or, if he or she was unavailable, a household member aged $\geq 18$ years was approached for an interview. In the qualitative study, there were 18 participants, 9 from the key informants (the town communication personnel, religious leaders, the town administrator, the town health bureau personnel, and volunteers of COVID-19 prevention and control task force, etc.) and the rest 9 from the general population.

\section{Operational Definition/Definition of Terms} Knowledge: - is the familiarity, awareness, or understanding of an event. Good knowledge was defined as a score greater than or equal to the mean value of knowledge items, and poor knowledge was defined as a score below the mean value. ${ }^{20-22}$
Perception of COVID-19:- is defined as a person's intuitive assessment of the disease to which they are or may be exposed. ${ }^{23}$

Perceived susceptibility: - is the subjective perception of the risk of acquiring an illness or disease. ${ }^{24}$ High perceived susceptibility was defined as a score greater than or equal to the mean value of perceived susceptibility items, and low perceived susceptibility was defined as a score below the mean value. ${ }^{25,26}$

Perceived severity: - is the feeling of the seriousness of contracting an illness or disease. ${ }^{24}$ High perceived severity was defined as a score greater than or equal to the mean value of perceived severity items, and low perceived severity was defined as a score below the mean value. ${ }^{25,26}$

Perceived Benefit: - is the perception of the effectiveness of various actions available to reduce the threat of the disease. ${ }^{24}$ High perceived benefit was defined as a score greater than or equal to the mean value of perceived benefit items, and low perceived benefit was defined as a score below the mean value. ${ }^{25,26}$

Perceived self-efficacy: - is a person's confidence in his or her own ability to successfully carry out a preventive behavior. ${ }^{24}$ High perceived self-efficacy was defined as a score greater than or equal to the mean value of perceived self-efficacy items, and low perceived self-efficacy was defined as a score below the mean value..$^{25,26}$

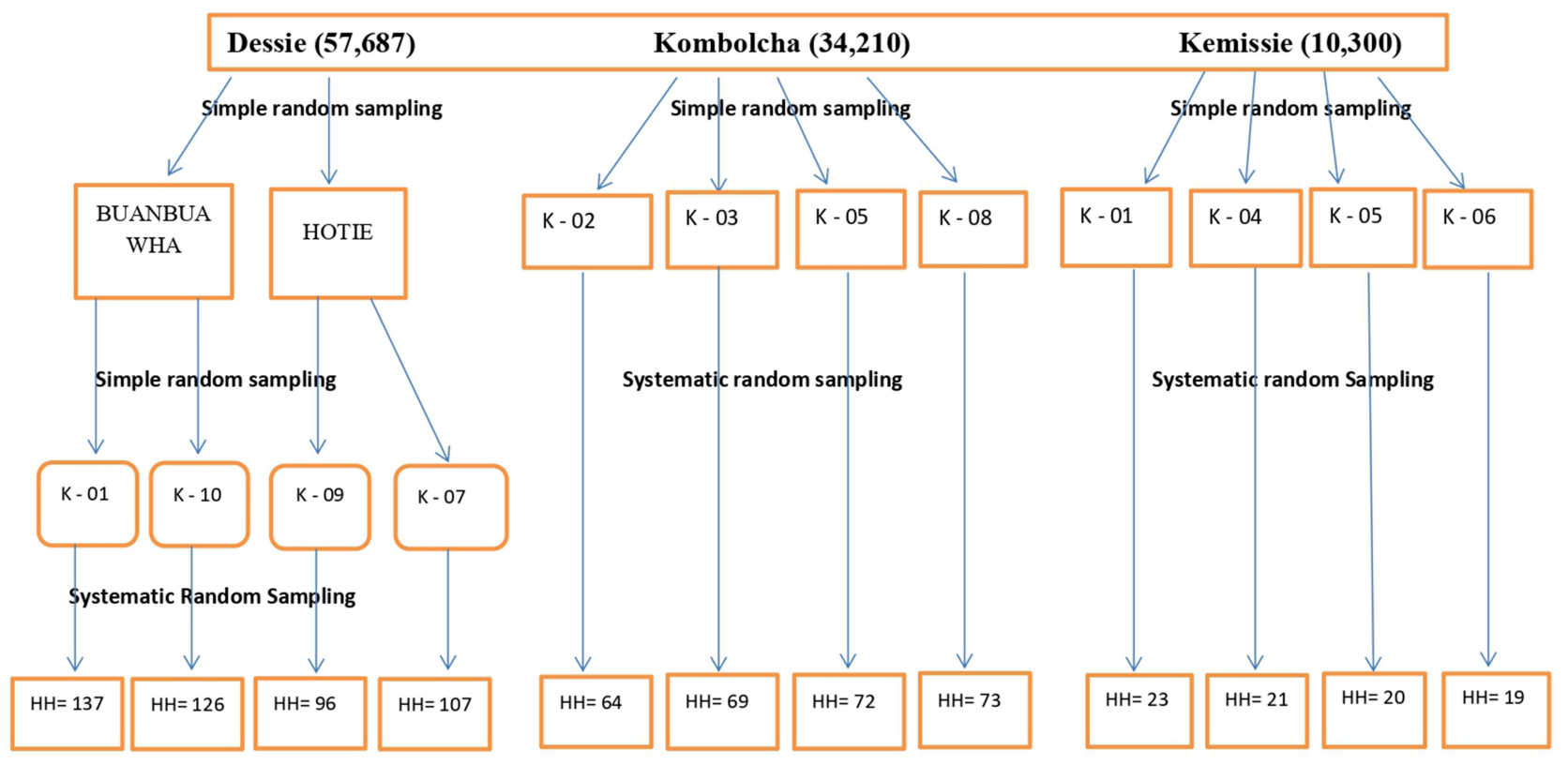

K: Kebele; HH: Household

Figure I Schematic presentation of sampling procedure in Dessie, Kombolcha, and Kemissie towns, Northeast Ethiopia ( $\mathrm{N}=827)$. 
Perceived barrier: - is the feeling of obstacles in performing a recommended health action. ${ }^{24}$ High perceived barrier was defined as a score greater than or equal to the mean value of perceived barrier items, and low perceived barrier was defined as a score below the mean value. ${ }^{25,26}$

Behavioral responses to Covid-19:- is defined as the practice of infection prevention measures recommended by the WHO to prevent COVID-19. Good behavioral response was defined as a score greater than or equal to the mean value of behavioral response items, and poor behavioral response was defined as a score below the mean value. ${ }^{21}$

\section{Data Collection Instrument}

The data were collected using semi-structured questionnaire adapted and modified from previous studies and guidelines. $^{27-29}$ The questionnaire comprises sociodemographic characteristics, health communication, knowledge, perception, and behavioral response items. The respondents' knowledge of COVID-19 was assessed using 20 yes/no/do not know questions. Furthermore, the health belief model was used to assess the respondents' perceptions, which consisted of 22 items (4, 4, 4, 5 , and 5 items for perceived susceptibility, severity, selfefficacy, benefits, and barriers, respectively) on a fivepoint Likert scale ranging from strongly disagree to strongly agree. Similarly, COVID-19 behavioral responses were assessed using 7 items on a five-point Likert scale ranging from never to always (Annex-I). Internal consistency of perception and behavioral response items was checked using Cronbach's Alpha $(\alpha)$. Cronbach's alpha values were $0.69,0.62,0.53$, $0.66,0.59$, and 0.78 for perceived susceptibility, perceived severity, perceived benefit, perceived self-efficacy, perceived barrier, and behavioral response items, respectively.

\section{Data Collection Procedure and Quality Control}

The data were collected by six BSc nurses using ODK collect and supervised by three MSc nurse professionals. Two days of training were given for data collectors and supervisors, and pretesting of the questionnaire was undertaken in $5 \%$ (43) of the total sample size in Haik town. Moreover, the principal investigators conducted regular supervision, immediate feedback, and daily checking of the completed data. Furthermore, the qualitative data were gathered through in-depth interview by using unstructured questions. The interviewer and note-taker were involved in the data collection, and the interview was tape-recorded. Before the analysis, field notes and audio recordings were reviewed for appropriate coding and clear audibility. The data collection process was carried out by considering and implementing COVID-19 infection prevention measures such as wearing a mask, using sanitizer, keeping an adequate distance from the respondent, etc.

\section{Data Processing and Analysis}

The collected data were downloaded from the ODK aggregate as an Excel file and exported to SPSS (Statistical Package for Social Sciences, version 25) for analysis. Descriptive statistics (frequency table, pie chart, and bar graph) were used to summarize the data. Bivariate logistic regression was used to check variables that had an association with the dependent variables, and those with a p-value $\leq 0.2$ were further analyzed using multiple logistic regression. Adjusted odds ratio with 95\% CI was computed, and variables that had a p-value $<0.05$ in the multiple logic regression were considered as significantly associated. The HosmerLemeshow goodness-of-fit test was used to assess the model's fitness $(P=0.13)$. For the qualitative data, a verbatim transcription in the Amharic language was made and then translated into the English language for further analysis. The translated text files were analyzed using a thematic content analysis based on codes and terminologies to create themes. Finally, the qualitative and quantitative findings were triangulated.

\section{Ethical Considerations}

Ethical clearance and approval were obtained from the Research Ethics and Approval Committee of Wollo University (RF: CMHS/357/2012). Besides, official letters were submitted to each town administration, and permission to conduct the study was obtained from the responsible authorities. After explaining the study objectives, informed consent for participation and publication of anonymized responses were obtained from each participant, and respondents have the right not to participate or withdraw from the study at any stage. Additionally, anonymity and confidentiality of the data were kept, and all study methods were performed in accordance with the declaration of Helsinki. 


\section{Results}

\section{Socio-Demographic Characteristics of the Respondents}

A total of 827 participants were involved in the quantitative study, resulting in a $98 \%$ response rate. Over half (56.3\%) of participants were from Dessie town, 57.2\% were females, and $12.9 \%$ were aged $<25$ years old (mean $\pm \mathrm{SD}, 39.2 \pm 13.8$ years). The majority $(67.1 \%$ ) of participants were married, 55.9\% were Muslim, 2.5\% lived alone, and $12.3 \%$ were not able to read and write. Only $9.2 \%$ of the respondents were farmers/daily laborers, $23 \%$ had an average monthly income of $\geq 5000 \mathrm{ETB}$, and $17.7 \%$ had a chronic illness (Table 1).

In the qualitative study, a total of 18 in-depth interviews were conducted. Half of the participants were key informants (COVID-19 prevention and control task force, town administrative, health bureau personnel, communication offices, and religious leaders), and the remaining 9 participants were from the general population. The majority of respondents $(72.2 \%)$ were males, and the respondents' ages ranged from 20-62 years (Table 2). After the interview, the respondent's ideas were transcribed, translated, coded, and categorized into six themes. The identified themes were; COVID-19 health communication, the community awareness of COVID-19, perception of COVID-19, the practice of COVID-19 preventive measures, factors related to COVID-19 preventive measures, and further activities to mitigate the spread of COVID-19.

\section{Health Communication of COVID-19}

The vast majority (91.8\%) of the respondents obtained information about COVID-19 daily, and $97.8 \%$ of the participants got information through broadcast media (Figures 2 and 3). Regarding the type of source of information, $94.4 \%$ obtained information through $\mathrm{TV}, 43.9 \%$ from the COVID-19 prevention and control task force, $43.2 \%$ through Facebook, 15.8\% from YouTube, and $13.9 \%$ from newspapers (Table 3).

Additionally, participants in the qualitative study reported that messages or information about coronavirus were communicated to the community via various channels such as television, radio, health professionals, volunteers, and religious leaders. This finding was supported by the idea of a 48-year-old male key informant.

" ... the communication center has tried to facilitate and provide COVID-19 media coverage using various options such as Dessie and Wollo FM radios. In addition, we have created videos that will be broadcast on Walta and Amhara Televisions". (Kd2g)

Corresponding with the above informant, a 35-year-old female key informant described the government's and community actors' communication efforts as follows:

"As volunteers, we carry out various COVID-19 prevention activities at different places. We have conducted awareness-creation programs using Montarbo, as well as demonstrated handwashing and wearing masks". (Kd4g)

The communication efforts and community mobilization campaigns were also witnessed by some interviewees. The following is the description of a 27-year-old female participant:

"I get information about COVID-19 from TV and Facebook. Furthermore, health professionals and volunteers had organized public awareness campaigns". (KP-5)

\section{Knowledge of COVID-19}

The mean \pm SD value of the knowledge score was 17.3 \pm 2.9 . Using the mean value as a cut point, $58.5 \%$ of respondents had good knowledge of COVID-19 (Figure 4). According to the qualitative study finding, the community has a basic understanding of the disease, and this was well described by various stakeholders. For example, a 48-year-old male informant said that:

"Every week, we try to assess the community's awareness of COVID-19 using various methods ... our finding indicated that the community is well-informed about the disease". (Kd2g)

A 37-year-old key informant further explains the issue as follows:

"The community is well-informed about the coronavirus ... they know the nature of the disease and preventive measures ...". (Kk6g)

Likewise, a 30-year-old female participant described the mode of transmission, signs and symptoms, and preventive methods of COVID-19 as follows:

"According to what we have learned, the coronavirus can be transmitted via airborne, handshaking, and touching different materials. The signs and symptoms include cough, fever, body ache (myalgia), and sore throat. The disease can be prevented by washing our hands, wearing a mask, using sanitizer, and maintaining physical distance". (DP-3) 
Table I Sociodemographic Characteristics of the Respondents in Dessie, Kombolcha, and Kemissie Towns, Northeast Ethiopia $(\mathrm{N}=827)$

\begin{tabular}{|c|c|c|}
\hline \multirow[t]{2}{*}{ Variables } & \multicolumn{2}{|c|}{ Frequency } \\
\hline & Number & Percent \\
\hline \multicolumn{3}{|l|}{ Name of the town } \\
\hline Dessie & 466 & $56.3 \%$ \\
\hline Kombolcha & 278 & $33.6 \%$ \\
\hline Kemissie & 83 & $10 \%$ \\
\hline \multicolumn{3}{|l|}{ Sex of participants } \\
\hline Female & 473 & $57.2 \%$ \\
\hline Male & 354 & $42.8 \%$ \\
\hline \multicolumn{3}{|l|}{ Age of respondents } \\
\hline$<25$ years & 107 & $12.9 \%$ \\
\hline $25-34$ years & 229 & $27.7 \%$ \\
\hline $35-44$ years & 224 & $27.1 \%$ \\
\hline $45-54$ years & 138 & $16.7 \%$ \\
\hline $55-64$ years & 83 & $10 \%$ \\
\hline$\geq 65$ years & 46 & $5.6 \%$ \\
\hline \multicolumn{3}{|l|}{ Marital status of respondents } \\
\hline Married & 555 & $67.1 \%$ \\
\hline Single & 160 & $19.3 \%$ \\
\hline Divorced & 28 & $3.4 \%$ \\
\hline Widowed & 73 & $8.8 \%$ \\
\hline Separated & 11 & $1.3 \%$ \\
\hline \multicolumn{3}{|l|}{ Religion of respondents } \\
\hline Orthodox & 349 & $42.2 \%$ \\
\hline Muslim & 462 & $55.9 \%$ \\
\hline Protestant & 16 & $1.9 \%$ \\
\hline \multicolumn{3}{|l|}{ Is there anyone living with you } \\
\hline Yes & 806 & $97.5 \%$ \\
\hline No & 21 & $2.5 \%$ \\
\hline \multicolumn{3}{|l|}{ Educational level of the respondents } \\
\hline Not able to read and write & 102 & $12.3 \%$ \\
\hline Able to read and write & 122 & $14.8 \%$ \\
\hline Primary education & 238 & $28.8 \%$ \\
\hline Secondary or above & 365 & $44.1 \%$ \\
\hline \multicolumn{3}{|l|}{ Average family monthly income } \\
\hline$<1000$ ETB & 194 & $23.4 \%$ \\
\hline 1000-2999 ETB & 325 & $39.3 \%$ \\
\hline 3000-4999 ETB & 118 & $14.3 \%$ \\
\hline$\geq 5000$ ETB & 190 & $23 \%$ \\
\hline \multicolumn{3}{|l|}{ Occupation of respondents } \\
\hline Housewife & 195 & $23.6 \%$ \\
\hline Merchant & 324 & $39.2 \%$ \\
\hline Employee & 178 & $21.5 \%$ \\
\hline Farmer/daily laborer & 76 & $9.2 \%$ \\
\hline No job & 54 & $6.5 \%$ \\
\hline
\end{tabular}

(Continued)
Table I (Continued).

\begin{tabular}{|l|l|l|}
\hline \multirow{2}{*}{ Variables } & \multicolumn{2}{|l|}{ Frequency } \\
\cline { 2 - 3 } & Number & Percent \\
\hline Do you have a chronic illness & & \\
No & 681 & $82.3 \%$ \\
Yes & 146 & $17.7 \%$ \\
\hline
\end{tabular}

\section{Perception of COVID-19}

The mean \pm SD score of perceived susceptibility and severity to COVID-19 were $15.26 \pm 2.02$ and $13.97 \pm 1.95$, respectively. Additionally, the mean $\pm \mathrm{SD}$ of perceived benefits, barriers, and self-efficacy to COVID-19 preventive measures were $15.84 \pm 1.67,12.02 \pm 3.31$, and 19.83 \pm 2.20 , respectively. Using the mean score as a cut point, $51.3 \%$ and $60.9 \%$ of the respondents had high perceived susceptibility and severity to COVID-19, respectively. Similarly, $73.8 \%, 35.1 \%$, and $74.2 \%$ of the respondents had high perceived benefits, barriers, and self-efficacy to COVID-19 preventive measures, respectively (Figure 5). Furthermore, the qualitative study discovered that the community's risk perception of COVID-19 was poor, particularly among youths. Additionally, the community's perception has also changed over time.

A 43-year-old religious leader stated that:

"When the coronavirus first occurred in Ethiopia, the community was terrified and took better precautions. However, this is no longer the case. COVID-19 is no longer causing as much fear in the community as it was before". (Kd1r)

Seemingly, a 52-year-old male participant described:

"When someone dies, we scream, cry, and then forget. Such a community adaptation is also seen in the COVID-19 outbreak. We were scared at first and took all precautionary measures hoping that the disease would be eradicated in a short time". (DP-4)

Another 56-year-old male informant added:

"Young people believe they are less likely to become infected with COVID-19 and that even if they do, they will be safe". (Kd3g)

Furthermore, a 45-year-old religious leader added:

"... as they said, the disease is like a common cold and does not kill unless there is comorbidity". (Kk7r) 
Table 2 Sociodemographic Characteristics of Qualitative Study Participants in Dessie, Kombolcha, and Kemissie Towns, Northeast Ethiopia $(\mathrm{N}=18)$

\begin{tabular}{|l|l|l|l|l|}
\hline Participant Code & Sex & Age & Date of Interview & Position \\
\hline Kd2g & M & 48 & $18 / 07 / 2020$ & Town communication office personnel \\
Kdlr & M & 43 & $20 / 07 / 2020$ & Religious leader \\
Kd3g & M & 56 & $18 / 07 / 2020$ & Town administrative personnel \\
Kd4g & F & 35 & $18 / 07 / 2020$ & Coordinator of voluntaries \\
Kd5r & M & 40 & $12 / 07 / 2020$ & Religious leader \\
Kk6g & M & 37 & $12 / 07 / 2020$ & Town communication office personnel \\
Kk7r & M & 45 & $12 / 07 / 2020$ & Religious leader \\
Kk9g & F & 33 & $12 / 07 / 2020$ & Town administrative personnel \\
Kk8r & M & 53 & $12 / 07 / 2020$ & Religious leader \\
Dp-I & M & 20 & $22 / 07 / 2020$ & - \\
Dp-2 & $M$ & $22 / 07 / 2020$ & - \\
Dp-3 & F & 42 & $22 / 07 / 2020$ & - \\
Dp-4 & M & 30 & $22 / 07 / 2020$ & - \\
Kp-I & M & 32 & $13 / 07 / 2020$ & - \\
Kp-2 & $M$ & $13 / 07 / 2020$ & - \\
Kp-3 & $M$ & $13 / 07 / 2020$ & - \\
kp-4 & F & 62 & $13 / 07 / 2020$ & - \\
Kp-5 & F & 25 & $13 / 07 / 2020$ & \\
\hline
\end{tabular}

\section{Behavioral Responses to COVID-19}

The mean \pm SD value of behavioral responses to COVID-

19 items was $26.44 \pm 6.40$, and by using the mean score as a cut point, $54.3 \%$ of the participants had good behavioral responses to COVID-19 (Figure 6). The finding of the qualitative study revealed that the Coronavirus prevention measures are currently not fully implemented and that the practice varies from place to place. Hand washing and wearing mask, for example, were primarily implemented in transportation and public services, but only rarely in other areas. A 52-year-old male participant stated that:

"COVID-19 preventive measures were well-implemented during the early disease outbreak. However, the handwashing stations that were previously located on the sidewalk are currently unavailable. In addition, no one wears a face mask or maintains physical distance in the bar, chat, and coffee houses". (DP-4)

Another 56 years old male key informant added:

"There is a gap in the continuous implementation of COVID-19 preventive measures ... the community might consider the disease as a one-time phenomenon, like the Spanish flu". (Kd3g)

A 30 years old female participant added:
“... hand hygiene and wearing mask are better practiced in banks and hotels. However, there is still a big gap in maintaining physical distance". (DP-3)

Another 42-year-old interviewee further elaborates the issue as:

" ... currently there is a significant gap in the implementation of COVID-19 preventative measures. The practice of hand hygiene, wearing mask and maintaining physical distance is poor, particularly among youth". (DP-2)

\section{Factors Associated with Behavioral Responses to COVID-19}

Residence, age, sex, marital status, level of education, average monthly income, occupation, having a chronic illness, access to print media, knowledge of COVID-19, perceived severity, and perceived benefits, barriers, and self-efficacy to COVID-19 preventive measures had a p-value $<0.2$ in the bivariate analysis. Further analysis of the above variables in the multivariate logistic regression showed that residence, age, level of education, knowledge of COVID-19, perceived barrier, and self-efficacy to preventive measures were significantly associated variables with the behavioral responses to COVID-19.

For instance, respondents who lived in Kombolcha town were 4.32 times more likely to have good behavioral 


\section{Frequency of getting information}

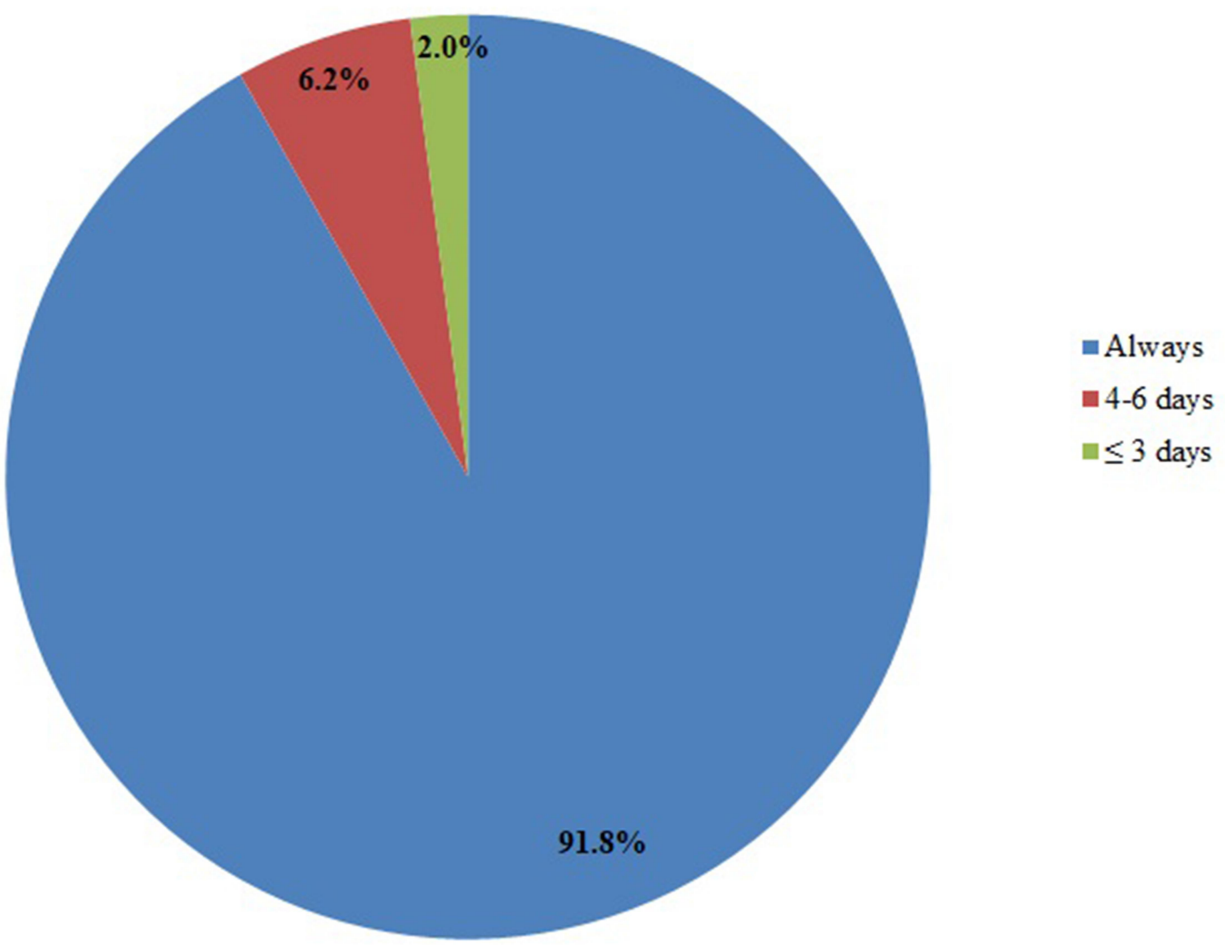

Figure 2 Frequency of obtaining information about COVID-19 in Dessie, Kombolcha, and Kemissie towns, Northeast Ethiopia (N=827).

responses than those who lived in Kemissie town ( $\mathrm{p}<$ 0.001 , AOR $=4.32,95 \%$ CI: 2.02-9.20). Likewise, participants aged from 25-34, and 35-44 years were 2.62, and 2.23 times more likely to have good behavioral responses to COVID-19 compared to those aged $<25$ years $(\mathrm{p}=$ $0.003, \mathrm{AOR}=2.62,95 \% \mathrm{CI}: 1.37-5.0)$, and $(\mathrm{p}=0.024$, $\mathrm{AOR}=2.23,95 \%$ CI: 1.11-4.46), respectively. Similarly, respondents who had secondary or above education had 2.38 times higher odds of good behavioral responses than those who cannot read and write $(\mathrm{p}=0.017, \mathrm{AOR}=2.38$, 95\% CI: 1.17-4.86). Furthermore, participants who had good knowledge of COVID-19 were 2.07 times more likely to have good behavioral responses to COVID-19 than those who had poor knowledge $(\mathrm{p}<0.001$, AOR $=$ 2.07, 95\% CI: 1.42-3.02). Additionally, respondents who had High perceived self-efficacy to COVID-19 preventive measures were 4.90 times more likely to have good behavioral responses to COVID-19 compared to those who had low percieved self-efficacy $(\mathrm{p}<0.001, \mathrm{AOR}=4.90,95 \%$ CI: 3.10-7.75). Finally, respondents who had low perceived barriers to preventive measures were 3.17 times more likely to have good behavioral responses to
COVID-19 compared to those who had high perceived barrier $(\mathrm{p}<0.001, \mathrm{AOR}=3.17,95 \%$ CI: $2.12-4.74)$ (Table 4).

Additionally, various factors related to COVID-19 preventive measures were identified in the qualitative study. Misinformation, economic factors, relating COVID-19 with politics, and carelessness are among them. For example, a 35-year-old female coordinator of volunteers stated:

"Misinformation from those in the quarantine centers is the main reason for the poor practice of COVID-19 preventive measures. They inform their friends and families that no specific intervention is being provided to them". $(\mathrm{Kd} 4 \mathrm{~g})$

A 52-year-old male participant stated:

" ... the poor practice of preventive measures may be related to the economic problems of the community. Staying at home is difficult because the problem may result in an inability to pay water bills". (DP-4)

Another 53-year-old male religious leader stated that: 


\section{Source of information}

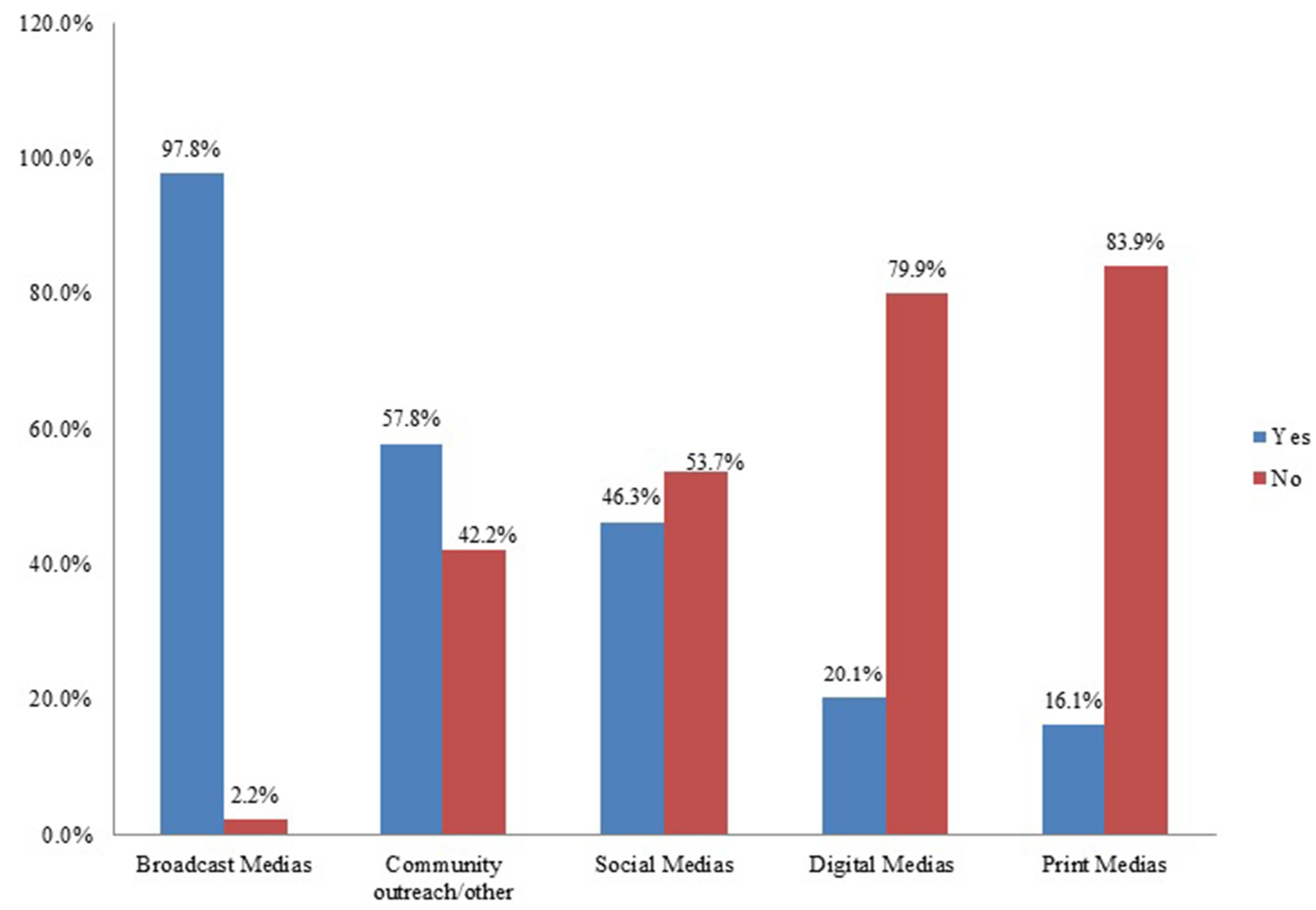

Figure 3 Sources of information to COVID-19 in Dessie, Kombolcha, and Kemissie towns, Northeast Ethiopia (N=827).

"The problem with society is that everything is considered as a political issue, which is not right ... There are many wrongdoings, such as imprisoning and punishing religious leaders, guarding mosques with soldiers, and sending more soldiers to church, etc". (KK8r)

Furthermore, 56-year-old town administrative personnel added:

"As you can see, there is a better practice of wearing a mask, but not in all societies. Youths, in particular, are not fully implementing preventive measures; there is a great deal of negligence and carelessness". (Kd3g)

Another theme identified in the qualitative study was further activities required to mitigate the spread of COVID-19. The participants identified future tasks expected from the government, COVID-19 prevention and control task forces, religious leaders, and the community. A 40-year-old religious leader said:
“ ... stakeholders' collaboration should be strengthened, and stakeholders should continuously work on the preventive measures of coronavirus. Furthermore, the community should avoid stigmatizing COVID-19 suspected cases and fully implement the state of emergency". (Kd5r)

A 33-year-old key informant added:

“. ... health education may not be successful if it is given only to the health sector because health communication requires the collaboration of various sectors". (KK9g)

Moreover, a 27-year-old female participant added:

"Health professionals should do what they can, and the community must listen to what is being said. Additionally, the government and COVID-19 prevention task force should educate the community about the severity of the disease. In this way, we can control the disease before it harms us". (KP-5) 
Table 3 The Type of Sources of Information to COVID-19 in Dessie, Kombolcha, and Kemissie Towns, Northeast Ethiopia $(\mathrm{N}=827)$

\begin{tabular}{|c|c|c|}
\hline \multirow[t]{2}{*}{ Variables } & \multicolumn{2}{|c|}{ Frequency } \\
\hline & Number & Percentage \\
\hline \multicolumn{3}{|l|}{ Broadcast Media } \\
\hline \multicolumn{3}{|l|}{ Television } \\
\hline Yes & 781 & $94.4 \%$ \\
\hline No & 46 & $5.6 \%$ \\
\hline \multicolumn{3}{|l|}{ Radio } \\
\hline Yes & 506 & $61.2 \%$ \\
\hline No & 321 & $38.8 \%$ \\
\hline \multicolumn{3}{|l|}{ Print Media } \\
\hline \multicolumn{3}{|l|}{ Newspaper } \\
\hline Yes & 115 & $13.9 \%$ \\
\hline No & 712 & $86.1 \%$ \\
\hline \multicolumn{3}{|l|}{ Books } \\
\hline Yes & 41 & $5 \%$ \\
\hline No & 786 & $95 \%$ \\
\hline \multicolumn{3}{|l|}{ Magazine } \\
\hline Yes & 83 & $10 \%$ \\
\hline No & 744 & $90 \%$ \\
\hline \multicolumn{3}{|l|}{ Folders/Brochures/flyers } \\
\hline Yes & 77 & $9.3 \%$ \\
\hline No & 750 & $90.7 \%$ \\
\hline
\end{tabular}

\begin{tabular}{|l|l|l|}
\hline \multicolumn{2}{|l|}{ Digital Media } & \\
\hline $\begin{array}{l}\text { Podcasts } \\
\text { Yes }\end{array}$ & 33 & $4 \%$ \\
No & 794 & $96 \%$ \\
\hline $\begin{array}{l}\text { Government Websites } \\
\text { Yes }\end{array}$ & 87 & \\
No & 740 & $10.5 \%$ \\
\hline YouTube & & $89.5 \%$ \\
Yes & 131 & \\
No & 696 & $15.8 \%$ \\
\hline Personal Blogs & & $84.2 \%$ \\
Yes & 9 & $1.1 \%$ \\
No & 818 & $98.9 \%$ \\
\hline
\end{tabular}

Social Media

\begin{tabular}{|l|l|l|}
\hline Facebook & & \\
Yes & 357 & $43.2 \%$ \\
No & 470 & $56.8 \%$ \\
\hline
\end{tabular}

(Continued)
Table 3 (Continued).

\begin{tabular}{|c|c|c|}
\hline \multirow[t]{2}{*}{ Variables } & \multicolumn{2}{|c|}{ Frequency } \\
\hline & Number & Percentage \\
\hline \multicolumn{3}{|l|}{ Telegram } \\
\hline Yes & 354 & $42.8 \%$ \\
\hline No & 473 & $57.2 \%$ \\
\hline \multicolumn{3}{|l|}{ Twitter } \\
\hline Yes & 39 & $4.7 \%$ \\
\hline No & 788 & $95.3 \%$ \\
\hline \multicolumn{3}{|l|}{ WhatsApp } \\
\hline Yes & 133 & $16.1 \%$ \\
\hline No & 694 & $83.9 \%$ \\
\hline \multicolumn{3}{|l|}{ Community outreach/others } \\
\hline \multicolumn{3}{|l|}{ Health care professionals } \\
\hline Yes & 216 & $26.1 \%$ \\
\hline No & 611 & $73.9 \%$ \\
\hline \multicolumn{3}{|l|}{ COVID-19 prevention task force } \\
\hline Yes & 363 & $43.9 \%$ \\
\hline No & 464 & $56.1 \%$ \\
\hline \multicolumn{3}{|l|}{ Public figure } \\
\hline Yes & 97 & $11.7 \%$ \\
\hline No & 730 & $88.3 \%$ \\
\hline \multicolumn{3}{|l|}{ Religious leaders } \\
\hline Yes & 251 & $30.4 \%$ \\
\hline No & 576 & $69.6 \%$ \\
\hline
\end{tabular}

\section{Discussion}

This study showed that the majority $(91.8 \%)$ of respondents obtained information about COVID-19 daily. The qualitative study also supports the above finding that there were adequate health education and awareness creation campaigns regarding COVID-19. However, the knowledge, perception (particularly, perceived susceptibility and severity), and behavioral responses to COVID-19 among the respondents were not satisfactory.

The majority of participants $(58.5 \%, 95 \%$ CI: $54.9-$ $62 \%$ ) had good knowledge of COVID-19. Comparable findings were reported from an online survey in Ethiopia $(55.9 \%),{ }^{30}$ and Bangladesh (54.87\%). ${ }^{31}$ This finding was lower than studies conducted in Addis Zemen hospital in Ethiopia $(66.1 \%){ }^{32}$ college students in Ethiopia $(69.6 \%),{ }^{33}$ Ghana $(62.7 \%){ }^{34}$ and Iran $\left.(79.6 \%)\right)^{35}$ 


\section{Knowledge of COVID-19}

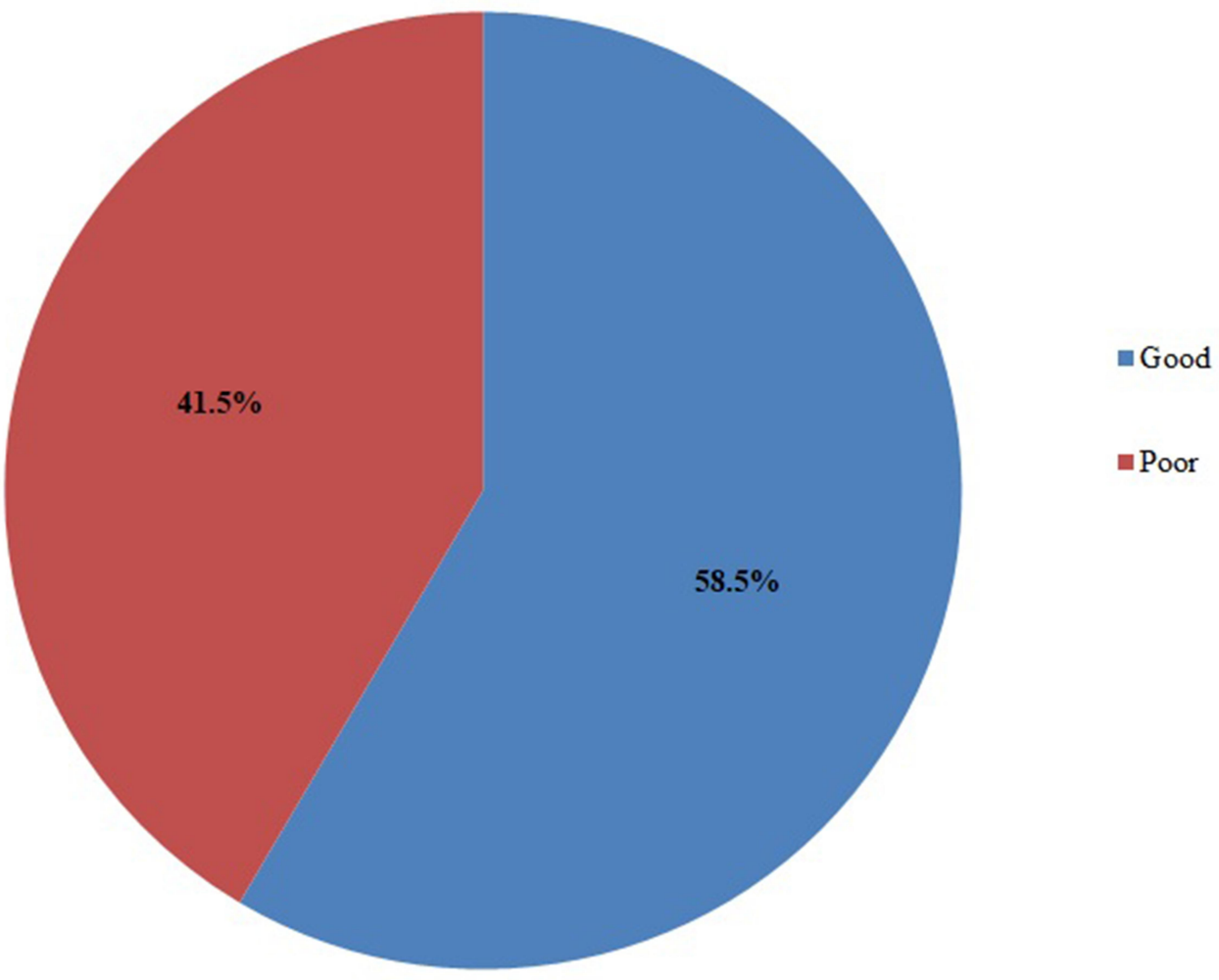

Figure 4 Respondents knowledge category to COVID-19 in Dessie, Kombolcha, and Kemissie towns, Northeast Ethiopia (N=827).

However, this finding was higher than other studies conducted in Debre Tabor, Ethiopia (54.2\%), ${ }^{36}$ community Pharmacists in Addis Ababa, Ethiopia (53.2\%), ${ }^{37}$ a national study in Ethiopia (42\%), ${ }^{38}$ and Bangladesh (45\%). ${ }^{39}$ The discrepancy might be attributed to the sociodemographic differences (level of education, profession, health condition, etc.), the scope of the study, and study settings.

Only $51.3 \%$ and $60.9 \%$ of participants had high perceived susceptibility and severity to COVID-19, respectively. The above finding indicated that the participants' perceived threats of COVID-19 were not adequate. The perceived susceptibility finding of this study showed lower results compared to other studies conducted in Addis Ababa, Ethiopia $(62.3 \%){ }^{25}$ and India (65.4\%). ${ }^{40}$ However, the perceived severity finding showed relatively higher results than other studies conducted in Addis Ababa, Ethiopia $(53.7 \%){ }^{25}$ and India $(55.7 \%) .{ }^{40}$ Additionally, this study showed that $73.8 \%, 74.2 \%$, and $35.1 \%$ of participants had high perceived benefits, selfefficacy, and barriers to COVID-19 preventive measures, respectively. The above finding indicated that the participants' perceived benefits and self-efficacy to COVID-19 preventive measures was relatively high compared to other studies in Ethiopia, ${ }^{25}$ and India. ${ }^{40}$ However, the perceived barriers to Covid-19 preventive measures showed significantly lower results compared to other studies in Ethiopia, ${ }^{25}$ and India. $^{40}$ These discrepancies might be attributed to the variations in the study setting and participants' professions.

Over half of the respondents $(54.3 \%, 95 \%$ CI: $50.8-$ $57.6 \%$ ) had good behavioral responses to COVID-19. The qualitative findings also revealed that the preventive measures of COVID-19 were not fully implemented in the community. Comparable results were reported from other studies conducted in Addis Zemen hospital, Ethiopia $(52.7 \%),{ }^{32}$ educated population in Ethiopia (54\%), ${ }^{30}$ and Bangladesh (52.4\%). ${ }^{41}$ However, higher results were reported in the studies from Amhara region, Ethiopia among college students $(65 \%),{ }^{33}$ a community-based survey in southwest Ethiopia (59.4\%), ${ }^{42}$ health care workers in Amhara region, Ethiopia (62\%), ${ }^{43}$ and Iran (94.2\%). ${ }^{35}$ 


\section{Frequency}

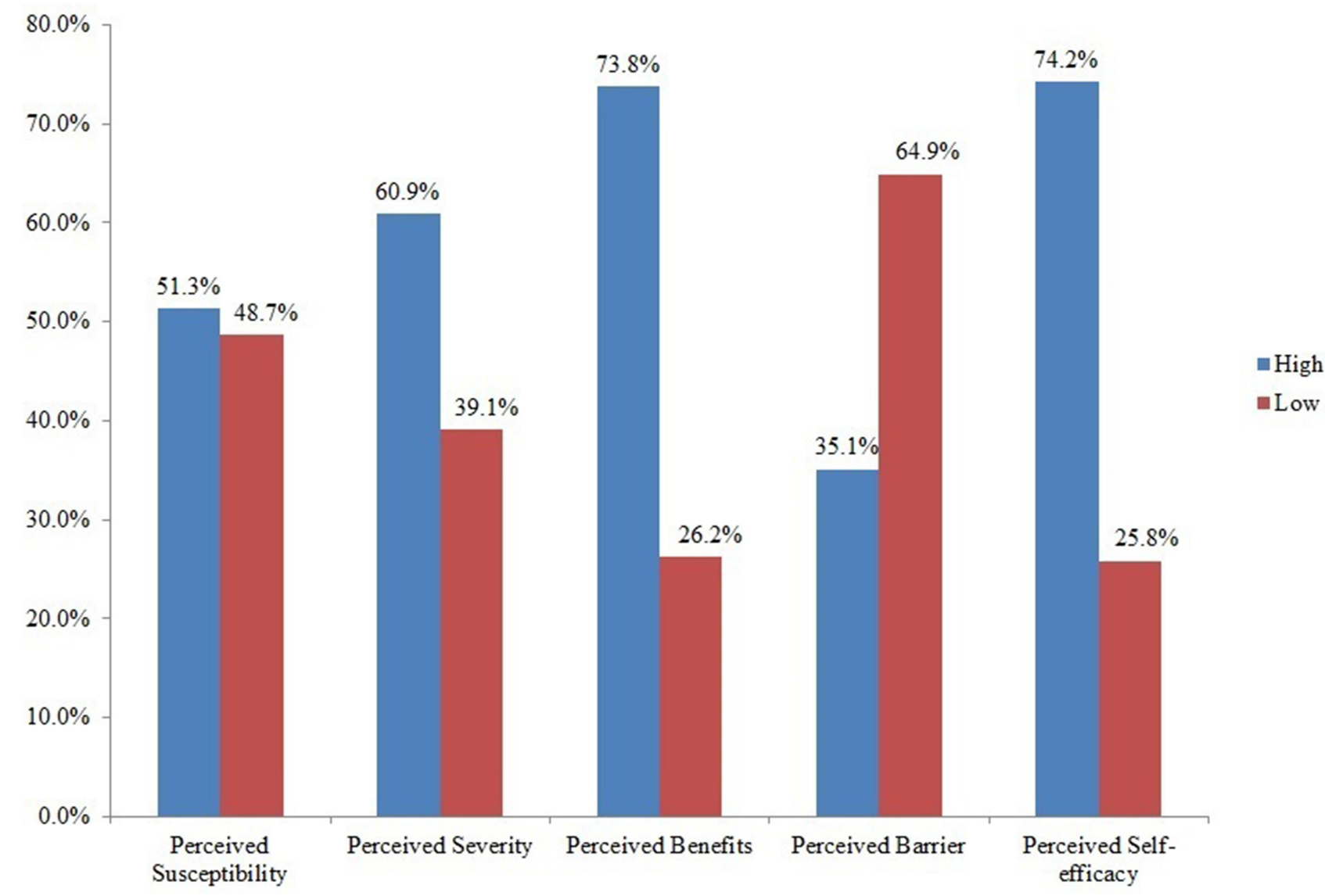

Figure 5 Respondents' perception classification to COVID-19 using the health belief model in Dessie, Kombolcha, and Kemissie towns, Northeast Ethiopia (N=827).

This discrepancy might be due to the variation in the participant's level of education and profession. On the other hand, lower findings were reported from a nationwide telephone interview in Ethiopia $(24.3 \%),{ }^{38}$ a community-based study in Southern Ethiopia (20\%), ${ }^{44}$ a hospitalbased study in Debre Tabor, Ethiopia (49\%), ${ }^{36}$ and Bangladesh (24\%). ${ }^{45}$ This discrepancy might be the result of variation in the scope of the study, study setting, and inclusion of rural areas.

Respondents who lived in Kombolcha town were 4.32 times more likely to have good behavioral responses than those who lived in Kemissie town. This might be due to the fact that Kombolcha town is located near the neighboring Afar region, which could be the gateway for COVID-19 from other countries such as Djibouti. Therefore, this condition might result in higher perceived risks that will lead to higher behavioral responses to COVID-19.
Study subjects aged 25-34 and 35-44 years were 2.62, and 2.23 times more likely to have good behavioral responses to COVID-19, respectively compared to those participants aged $<25$ years. Similarly, in the in-depth interviews, participants explained that COVID-19 risk perception and behavioral responses were relatively poor among youths. Teens and young adults are ignorant of COVID-19 preventive measures for a variety of reasons, including underestimating the risk, believing they are not at risk and a lack of accountability. ${ }^{46}$ The finding is in line with other studies conducted in Ethiopia, ${ }^{30,47}$ and India. ${ }^{48}$

Respondents who had secondary or above education had 2.38 times higher odds of good behavioral responses to COVID-19 compared to those who cannot read and write. Educated individuals may easily understand the nature of the disease and better implement preventive measures. Other studies conducted in Ethiopia ${ }^{38,49-51}$ and India $^{48}$ reported similar findings. 


\section{Behavioral response}

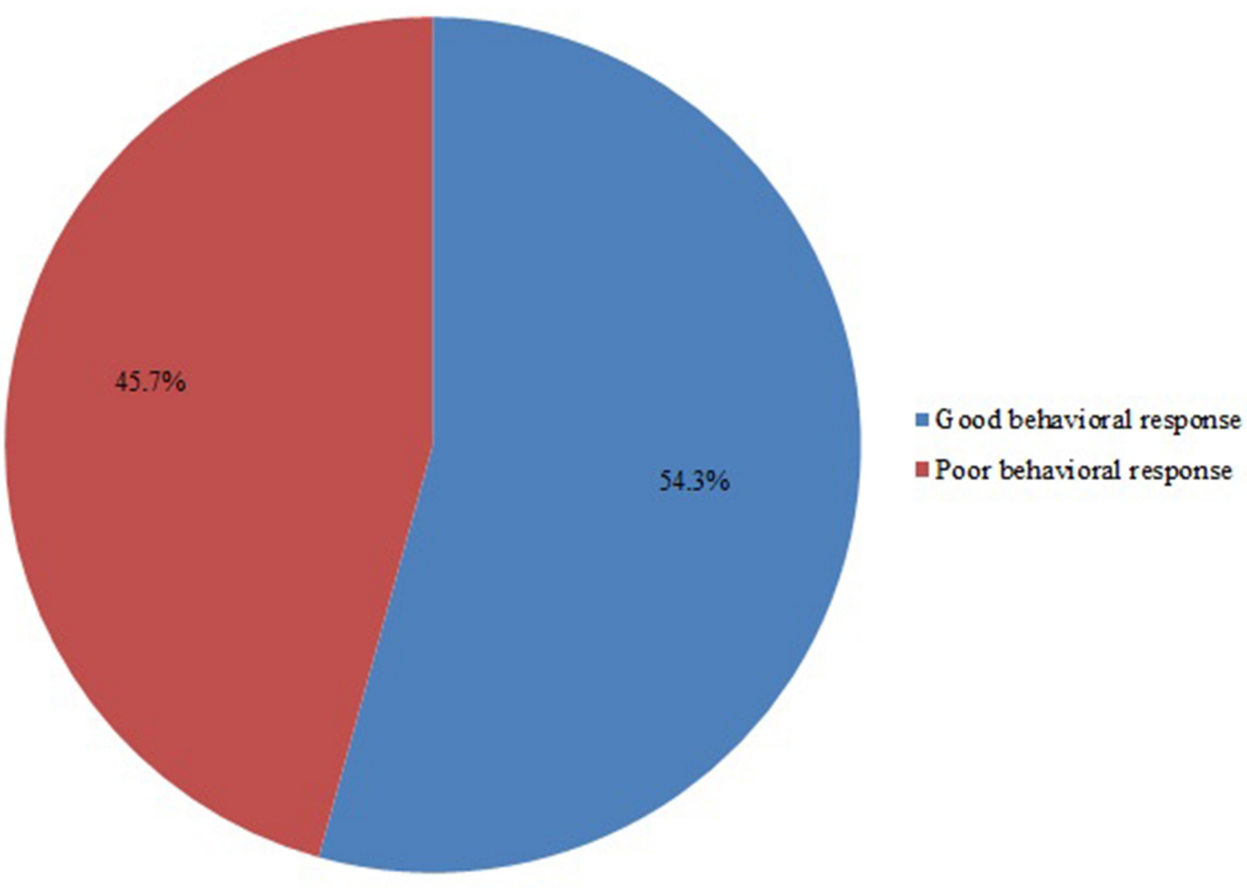

Figure 6 Respondents' behavioral responses classification to COVID-19 in Dessie, Kombolcha, and Kemissie towns, Northeast Ethiopia (N=827).

Participants who had good knowledge of COVID-19 were 2.07 times more likely to have good behavioral responses to COVID-19 than those who had poor knowledge. Having adequate knowledge of COVID-19 mode of transmission, signs and symptoms, and prevention might result in better behavioral responses to COVID-19. Related studies in Ethiopia, ${ }^{30,36,43,49,52}$ the Democratic Republic of Congo, ${ }^{53}$ and Kerala India ${ }^{54}$ reported similar findings.

Furthermore, respondents who had high perceived selfefficacy to COVID-19 preventive measures were 4.90 times more likely to have good behavioral responses to COVID-19. Self-efficacy is an important determinant of health-related behavioral change. ${ }^{55}$ Therefore, behavioral change might be facilitated by enhancing perceived selfefficacy. ${ }^{56}$ Studies conducted in Ethiopia, ${ }^{25}$ Northern Iran, ${ }^{57}$ and India ${ }^{54}$ showed similar results.

Finally, respondents who had low perceived barriers to COVID-19 preventive measures were 3.17 times more likely to have good behavioral responses compared to those who had high perceived barriers. Perceived barriers to healthy behaviors are the single most significant predictor of healthy behavioral responses. ${ }^{58}$ Similar results were reported from studies conducted in Ethiopia, ${ }^{25}$ Northern Iran, ${ }^{57}$ and India. ${ }^{54}$

\section{Conclusion}

The participant's perceived threat (susceptibility and severity), knowledge, and behavioral responses to COVID-19 were relatively low in this study. Similarly, the qualitative study also revealed that the preventive practices of COVID-19 were not fully implemented in the community. Residence, age of the respondent, level of education, knowledge of COVID-19, and perceived self-efficacy and barriers to COVID-19 preventive measures were significantly associated variables with the participants' behavioral responses to COVID-19 preventive practices. Therefore, stakeholders should collaborate to 
Table 4 Factors Associated with Behavioral Responses to COVID-19 in Dessie, Kombolcha, and Kemissie Towns, Northeast Ethiopia $(\mathrm{N}=827)$

\begin{tabular}{|c|c|c|c|c|c|}
\hline \multirow[t]{2}{*}{ Variables } & \multicolumn{2}{|c|}{ Behavioral Response to COVID-19 } & \multirow[t]{2}{*}{ COR $(95 \% \mathrm{Cl})$} & \multirow[t]{2}{*}{ AOR $(95 \% \mathrm{Cl})$} & \multirow[t]{2}{*}{ P-value } \\
\hline & Good & Poor & & & \\
\hline \multicolumn{6}{|l|}{ Town } \\
\hline Dessie & $232(28 \%)$ & $234(28.3 \%)$ & $2.93(1.73-4.96)$ & $\mathrm{I} .43(0.7 \mathrm{I}-2.86)$ & 0.32 \\
\hline Kombolcha & $196(23.7 \%)$ & $82(9.9 \%)$ & $7.06(4.04-12.3)$ & $4.32(2.02-9.2)^{*}$ & 0.000 \\
\hline Kemissie & $21(2.5 \%)$ & $62(7.5 \%)$ & 1 & 1 & \\
\hline \multicolumn{6}{|l|}{ Age } \\
\hline$<25$ years & $53(6.4 \%)$ & $54(6.5 \%)$ & 1 & I & \\
\hline $25-34$ years & 135 (16.3\%) & 94 (II.4\%) & $1.46(0.92-2.32)$ & $2.62(1.37-5.0)^{*}$ & 0.003 \\
\hline $35-44$ years & $125(15.1 \%)$ & 99 (I2\%) & $1.29(0.81-2.04)$ & $2.23(1.11-4.46)^{*}$ & 0.024 \\
\hline $45-54$ years & $73(8.8 \%)$ & $65(7.9 \%)$ & $1.14(0.69-1.90)$ & $1.49(0.68-3.23)$ & 0.32 \\
\hline $55-64$ years & $43(5.2 \%)$ & $40(4.8 \%)$ & $1.10(0.62-1.94)$ & $2.02(0.80-5.10)$ & 0.14 \\
\hline$\geq 65$ years & $20(2.4 \%)$ & $26(3.2 \%)$ & $0.78(0.39-1.57)$ & $1.70(0.57-5.12)$ & 0.35 \\
\hline \multicolumn{6}{|l|}{ Sex } \\
\hline Male & 169 (20.4\%) & 185 (22.4\%) & $0.63(0.48-0.83)$ & $0.8(0.52-1.23)$ & 0.31 \\
\hline Female & $280(33.9 \%)$ & $193(23.3 \%)$ & 1 & I & \\
\hline \multicolumn{6}{|l|}{ Marital status } \\
\hline Married & 331 (40\%) & $224(27.1 \%)$ & $2.24(1.36-3.69)$ & $1.32(0.64-2.70)$ & 0.45 \\
\hline Single & $69(8.3 \%)$ & $91(11 \%)$ & $1.15(0.66-2.02)$ & $0.80(0.33-1.95)$ & 0.63 \\
\hline Divorced/separated & $20(2.4 \%)$ & $19(2.3 \%)$ & $1.59(0.73-3.50)$ & $\mathrm{I} .4 \mathrm{I}(0.5 \mathrm{I}-3.87)$ & 0.51 \\
\hline Widowed & 29 (3.5\%) & 44 (3.4\%) & 1 & 1 & \\
\hline \multicolumn{6}{|l|}{ Level of education } \\
\hline Cannot read and write & 35 (4.2\%) & 67 (8.1\%) & 1 & 1 & \\
\hline Read and write & $52(6.3 \%)$ & $70(8.5 \%)$ & $1.42(0.83-2.50)$ & $178(0.84-3.78)$ & 0.14 \\
\hline Primary education & 130 (I5.7\%) & $108(13.1 \%)$ & $2.30(1.42-3.73)$ & I.7| (0.85-3.42) & 0.13 \\
\hline Secondary or above & $232(28.1 \%)$ & $133(16.0 \%)$ & $3.34(2.10-5.30)$ & $2.38(1.17-4.86)^{*}$ & 0.017 \\
\hline \multicolumn{6}{|l|}{ Monthly Family income } \\
\hline$<1000$ & 97 (II.7\%) & 97 (II.7\%) & 1 & 1 & \\
\hline $1000-2999$ & 173 (20.9\%) & $152(18.4 \%)$ & $1.14(0.80-1.63)$ & $0.89(0.52-I .5 I)$ & 0.65 \\
\hline $3000-4999$ & $66(8 \%)$ & $52(6.3 \%)$ & $1.27(0.80-2.01)$ & $0.94(0.46-1.91)$ & 0.85 \\
\hline$\geq 5000$ & $113(13.7 \%)$ & 77 (9.3\%) & $1.47(0.90-2.20)$ & $1.07(0.54-2.12)$ & 0.84 \\
\hline \multicolumn{6}{|l|}{ Occupation } \\
\hline Housewife & 117 (14.1\%) & $78(9.4 \%)$ & 1 & 1 & \\
\hline Merchant & $160(19.3 \%)$ & $164(19.8 \%)$ & $0.65(0.45-0.93)$ & $0.91(0.54-1.54)$ & 0.73 \\
\hline Employed & 115 (13.9\%) & $63(7.6 \%)$ & $1.22(0.80-1.85)$ & $1.26(0.68-2.32)$ & 0.46 \\
\hline Farmer/daily laborer & $28(3.4 \%)$ & $48(5.8 \%)$ & $0.39(0.23-0.67)$ & I.0I (0.47-2.17) & 0.98 \\
\hline No job & 29 (3.5\%) & $25(3 \%)$ & $0.77(0.42-1.42)$ & $1.32(0.53-3.25)$ & 0.55 \\
\hline \multicolumn{6}{|l|}{ Chronic illness } \\
\hline Yes & $82(9.9 \%)$ & 64 (7.7\%) & $1.10(0.77-1.57)$ & $1.36(0.82-2.26)$ & 0.23 \\
\hline No & 367 (43.5\%) & $314(38.9 \%)$ & I & 1 & \\
\hline \multicolumn{6}{|l|}{ Printing media } \\
\hline Yes & 85 (10.3\%) & $48(5.8 \%)$ & $1.61(1.09-2.36)$ & $1.36(0.82-2.26)$ & 0.23 \\
\hline No & 364 (44\%) & $330(39.9 \%)$ & I & 1 & \\
\hline \multicolumn{6}{|l|}{ Knowledge of COVID-19 } \\
\hline Good & 334 (34.7\%) & $150(23.8 \%)$ & $4.41(3.29-5.93)$ & $2.07(1.42-3.02)^{*}$ & 0.000 \\
\hline Poor & II5 (I6.6\%) & $228(24.9 \%)$ & I & 1 & \\
\hline
\end{tabular}

(Continued) 
Table 4 (Continued).

\begin{tabular}{|c|c|c|c|c|c|}
\hline \multirow[t]{2}{*}{ Variables } & \multicolumn{2}{|c|}{ Behavioral Response to COVID-I9 } & \multirow[t]{2}{*}{ COR $(95 \% \mathrm{Cl})$} & \multirow[t]{2}{*}{ AOR $(95 \% \mathrm{Cl})$} & \multirow[t]{2}{*}{ P-value } \\
\hline & Good & Poor & & & \\
\hline \multicolumn{6}{|l|}{ Perceived severity } \\
\hline High & $293(35.4 \%)$ & $211(25.5 \%)$ & $1.49(1.12-1.97)$ & $1.19(0.82-1.70)$ & 0.36 \\
\hline Low & $156(18.9 \%)$ & $167(20.2 \%)$ & 1 & 1 & \\
\hline \multicolumn{6}{|l|}{ Perceived benefit } \\
\hline High & $35 I(42.4 \%)$ & $259(31.3 \%)$ & $1.65(1.21-2.25)$ & $1.26(0.82-1.93)$ & 0.30 \\
\hline Low & 98 (11.9\%) & $119(14.4 \%)$ & 1 & 1 & \\
\hline \multicolumn{6}{|l|}{ Perceived barrier } \\
\hline High & $8 \mathrm{l}(9.8 \%)$ & 209 (25.3\%) & 1 & I & \\
\hline Low & $368(44.5)$ & $169(20.4 \%)$ & $5.62(4.10-7.70)$ & $3.17(2.12-4.74)^{*}$ & 0.000 \\
\hline \multicolumn{6}{|l|}{ Perceived self-efficacy } \\
\hline High & $4 I I(49.7 \%)$ & $203(24.5 \%)$ & $9.32(6.32-13.8)$ & $4.90(3.10-7.75)^{*}$ & 0.000 \\
\hline Low & $38(4.6 \%)$ & $175(21.2 \%)$ & 1 & 1 & \\
\hline
\end{tabular}

Note: *Significantly associated variables at $95 \% \mathrm{Cl}$.

address the barriers to practicing COVID-19 preventive measures and undertake continuous awareness creation programs to scale up the community's knowledge and perceived self-efficacy to COVID-19 preventive measures. Furthermore, the general public, especially young people, should follow the government's COVID-19 prevention and control rules and regulations.

\section{Abbreviations}

AOR, adjusted odds ratio; CI, confidence interval; ETB, Ethiopian Birr; ODK, open data kit; SD, standard deviation; SPSS, Statistical Package and Service Solution; TV, television; WHO, World Health Organization.

\section{Data Sharing Statement}

The data used to support the findings of this study is available from the corresponding author upon request.

\section{Acknowledgment}

We would like to thank Wollo University for allowing us to conduct the study, and our special thanks go to our colleagues for their valuable comments in the write-up of this research report. We would also like to thank data collectors and respondents for their invaluable support.

\section{Funding}

This study was financially supported by Wollo University.

\section{Disclosure}

The authors report no conflict of interest in this work.

\section{References}

1. Zhu N, Zhang D, Wang W, et al. A novel coronavirus from patients with pneumonia in China, 2019. N Eng J Med. 2020;382(8):727-733. doi:10.1056/NEJMoa2001017

2. Guo Y-R, Cao Q-D, Hong Z-S, et al. The origin, transmission and clinical therapies on coronavirus disease 2019 (COVID-19) outbreak-an update on the status. Mil Med Res. 2020;7(1):1-10. doi:10.1186/s40779-020-00240-0

3. Worldometer. Coronavirus Update (Live). Available from: https:// www.worldometers.info/coronavirus/. Accessed February, 2021.

4. World Health Organisation. WHO Coronavirus Disease (COVID-19) Dashboard. Available from: https://covid19.who.int/table. Accessed February, 2021.

5. World Bank. Assessing Ethiopian women's vulnerability to the COVID-19 pandemic; 2020. Available from: https://blogs.world bank.org/africacan/assessing-ethiopian-womens-vulnerability-covid19-pandemic. Accessed 2020

6. World economic forum. No refuge: the impact of coronavirus on the world's most vulnerable. Available from: https://www.weforum.org/ agenda/2020/04/covid-19-coronavirus-vulnerable-refugees/. Accessed 2020.

7. The New Work Times. Africa Braces for Coronavirus, but Slowly. Available from: https://www.nytimes.com/2020/03/17/world/africa/ coronavirus-africa-burkina-faso.html. Accessed 2020.

8. Limenih G. COVID-19 in Ethiopia: challenges, best practices, and prospects. Humanitarian Health Ethics. 2020.

9. World Health Organisation. Coronavirus disease (COVID-19) advice for the public. Available from: https://www.who.int/emergencies/dis eases/novel-coronavirus-2019/advice-for-public. Accessed 2020.

10. EMOH. Ethiopia confirmed the first case of COVID-19. Available from: https://www.ephi.gov.et/images/pictures/pic_2011/pic_2012/ First-English-Press-release-1.pdf. Accessed 2020.

11. Thomas RK. Health Communication. Springer Science \& Business Media; 2006. 
12. OLCreate. Health education, advocacy and community mobilisation. Available from: https://www.open.edu/openlearncreate/mod/oucon tent/view.php?id=164\&section=20.5. Accessed 2021 .

13. Mheidly N, Fares J. Leveraging media and health communication strategies to overcome the COVID-19 infodemic. J Public Health Policy. 2020;41(1):1-11. doi:10.1057/s41271-019-00190-5

14. Finset A, Bosworth H, Butow P, et al. Effective health communication-a key factor in fighting the COVID-19 pandemic. Patient Educ Couns. 2020;103(5):873. doi:10.1016/j.pec.2020.03.027

15. PHAO. Guidelines for communicating about coronavirus disease 2019. Available from: https://iris.paho.org/bitstream/handle/10665.2/ 52391/PAHOCMUPACOVID-1920004_eng.pdf? sequence= 1\&isAllowed=y. Accessed 2021.

16. Asefa A, Qanche Q, Hailemariam S, Dhuguma T, Nigussie T. Risk Perception Towards COVID-19 and its associated factors among waiters in selected towns of Southwest Ethiopia. Risk Manag Healthc Policy. 2020;13:2601. doi:10.2147/RMHP.S276257

17. Kebede Y, Birhanu Z, Fufa D, et al. Myths, beliefs, and perceptions about COVID-19 in Ethiopia: a need to address information gaps and enable combating efforts. PLoS One. 2020;15(11):e0243024. doi:10.1371/journal.pone.0243024

18. Deressa W, Worku A, Amogne W, Getachew S, Kifle A, Abebe W. Knowledge and perceptions of COVID-19 among government employees in Ethiopia. medRxiv. 2020.

19. CSA-Ethiopia. Population projection - central statistics agency of Ethiopia; 2019. Available from: https://www.statsethiopia.gov.et/wpcontent/uploads/2019/11/Projected-Population-of-Ethiopia20112019.pdf. Accessed 2020.

20. Kassie BA, Adane A, Tilahun YT, Kassahun EA, Ayele AS, Belew AK. Knowledge and attitude towards COVID-19 and associated factors among health care providers in Northwest Ethiopia. PLoS One. 2020;15(8):e0238415. doi:10.1371/journal.pone.0238415

21. Tadesse DB, Gebrewahd GT, Demoz GT. Knowledge, attitude, practice and psychological response toward COVID-19 among nurses during the COVID-19 outbreak in northern Ethiopia, 2020. New Microbes New Infect. 2020;38:100787. doi:10.1016/j. nmni.2020.100787

22. Ejeh FE, Saidu AS, Owoicho S, et al. Knowledge, attitude, and practice among healthcare workers towards COVID-19 outbreak in Nigeria. Heliyon. 2020;6(11):e05557. doi:10.1016/j.heliyon.2020.e05557

23. Rohrmann B. Risk isal. In Proceedings of The International Emergency Management Society Annual Conference, Prague, Czech Republic;June 2008: 17-19.

24. LaMorte WW. The health belief model. Boston University School of Public Health; 2019. Available from: https://sphweb.bumc.bu.edu/ ot lt/mph-modules/sb/behavioralchangetheories/ BehavioralChangeTheories2.html. Accessed 2021.

25. Tadesse T, Alemu T, Amogne G, Endazenaw G, Mamo E. Predictors of Coronavirus Disease 2019 (COVID-19) prevention practices using health belief model among employees in Addis Ababa, Ethiopia, 2020. Infect Drug Resist. 2020;13:3751. doi:10.2147/IDR.S275933

26. Shewasinad Yehualashet S, Asefa KK, Mekonnen AG, et al. Predictors of adherence to COVID-19 prevention measure among communities in North Shoa Zone, Ethiopia based on health belief model: a cross-sectional study. PLoS One. 2021;16(1):e0246006. doi:10.1371/journal.pone.0246006

27. Atchison CJ, Bowman L, Vrinten C, et al. Perceptions and behavioural responses of the general public during the COVID-19 pandemic: a cross-sectional survey of UK Adults. MedRxiv. 2020.

28. On K K, Kin Kit L, Henry Ho Hin C, et al. Community responses during early phase of COVID-19 epidemic, Hong Kong. Emerg Infect Dis J. 2020;26(7).

29. World Health Organisation. Survey tool and guidance. Available from: http://www.euro.who.int/_data/assets/pdf_file/0007/436705/ COVID-19-survey-tool-and-guidance.pdf?ua=1. Accessed 2020.
30. Dagne H, Alemu KA, Dagnew B, et al. Prevention practice and associated factors of coronavirus disease 2019 (COVID-19) outbreak among educated ethiopians: an online based cross-sectional survey; 2020.

31. Haque T, Hossain KM, Bhuiyan MMR, et al. Knowledge, attitude and practices (KAP) towards COVID-19 and assessment of risks of infection by SARS-CoV-2 among the Bangladeshi population: an online cross sectional survey; 2020.

32. Akalu Y, Ayelign B, Molla MD. Knowledge, attitude and practice towards COVID-19 among chronic disease patients at Addis Zemen Hospital, Northwest Ethiopia. Infect Drug Resist. 2020;13:1949. doi:10.2147/IDR.S258736

33. Tadesse AW, Melese N, Eshetie S, Chane M, Ali A. Knowledge, attitude, and practice and associated factors towards COVID-19 among college students in amhara region, ethiopia; a cross-sectional study; 2020.

34. Serwaa D, Lamptey E, Appiah AB, Senkyire EK, Ameyaw JK. Knowledge, risk perception and preparedness towards coronavirus disease-2019 (COVID-19) outbreak among Ghanaians: a quick online cross-sectional survey. Pan Afr Med J. 2020;35(Supp 2):44. doi:10.11604/pamj.supp.2020.35.2.22630

35. Taghrir MH, Borazjani R, Shiraly R. COVID-19 and Iranian medical students; a survey on their related-knowledge, preventive behaviors and risk perception. Arch Iran Med. 2020;23(4):249-254. doi:10.34172/aim.2020.06

36. Desie Emiru T, Birlie TA, Tasew SF, Amare AT, Tibebu NS, Tiruneh CM. Assessment of knowledge, practice and associated factors towards prevention of novel corona virus among clients attending at Debre Tabor General Hospital Debre Tabor Town, North West Ethiopia, 2020: institutional Based Cross-Sectional Study; 2020.

37. Tesfaye ZT, Yismaw MB, Negash Z, Ayele AG. COVID-19-related knowledge, attitude and practice among hospital and community pharmacists in Addis Ababa, Ethiopia. Integr Pharm Res Pract. 2020;9:105. doi:10.2147/IPRP.S261275

38. Negera E, Demissie TM, Tafess K. Inadequate level of knowledge, mixed outlook and poor adherence to COVID-19 prevention guideline among Ethiopians. BioRxiv. 2020.

39. Ferdous MZ, Islam MS, Sikder MT, Mosaddek ASM, ZegarraValdivia J, Gozal D. Knowledge, attitude, and practice regarding COVID-19 outbreak in Bangladesh: an online-based cross-sectional study. PLoS One. 2020;15(10):e0239254. doi:10.1371/journal. pone. 0239254

40. Jose R, Narendran M, Bindu A, Beevi N, Manju L, Benny P. Public perception and preparedness for the pandemic COVID 19: a health belief model approach. Clin Epidemiol Glob Health. 2021;9:41-46.

41. Paul A, Sikdar D, Hossain MM, et al. Knowledge, attitudes, and practices toward the novel coronavirus among Bangladeshis: implications for mitigation measures. PLoS One. 2020;15(9):e0238492. doi:10.1371/journal.pone.0238492

42. Wondimu W, Ejigu AG, Mekonen MA, et al. Practice of coronavirus disease-19 prevention methods and associated factors in three zones of Southwest Ethiopia: community based cross-sectional study; 2020.

43. Asemahagn MA. Factors determining the knowledge and prevention practice of healthcare workers towards COVID-19 in Amhara region, Ethiopia: a cross-sectional survey. Trop Med Health. 2020;48(1):111. doi:10.1186/s41182-020-00254-3

44. Mola S, Aweke Z, Jemal B, et al. Magnitude and associated factors for attitude and practice toward covid-19 and its prevention among the residents of Gedeo Zone, Southern Ethiopia: a Community-Based Cross-Sectional Study. Risk Manag Healthc Policy. 2021;14:253. doi:10.2147/RMHP.S277904

45. Rabbani MG, Akter O, Hasan MZ, Samad N, Mahmood SS, Joarder T. Knowledge, attitude and practice towards COVID-19 among people in Bangladesh during the pandemic: a cross-sectional study. medRxiv. 2020. 
46. Child \& Adolescent Behavioral Health. Reckless Youth Attitude: I will not get COVID-19; 2020. Available from: https:/www.childan dadolescent.org/reckless-youth-attitude-i-will-not-get-covid-19/. Accessed 2020.

47. Defar A, Molla G, Abdella S, et al. Knowledge, practice and associated factors towards the prevention of COVID-19 among high-risk groups: a cross-sectional study in Addis Ababa, Ethiopia. medRxiv. 2020.

48. Narayana G, Pradeepkumar B, Ramaiah JD, Jayasree T, Yadav DL, Kumar BK. Knowledge, perception, and practices towards COVID-19 pandemic among general public of India: a cross-sectional online survey. Curr Med Res Pract. 2020;10(4):153-159. doi:10.1016/j. cmrp.2020.07.013

49. Ayele AD, Mihretie GN, Belay HG, Teffera AG, Kassa BG, Amsalu BT. Knowledge and practice to prevent against corona virus disease (covid-19) and its associated factors among pregnant women in Debre Tabor Town Northwest Ethiopia: a Community Based Cross-Sectional Study. PLoS One. 2020;15(9). doi:10.1371/journal.pone.0238293

50. Mola S, Aweke Z, Jemal B, et al. Magnitude and associated factors for attitude and practice of Southern Ethiopian residents toward COVID19 and its preventions: a community based cross sectional study; 2020 .

51. Andarge E, Fikadu T, Temesgen R, et al. Intention and practice on personal preventive measures against the COVID-19 pandemic among adults with chronic conditions in Southern Ethiopia: a survey using the theory of planned behavior. $J$ Multidiscip Healthc. 2020;13:1863. doi:10.2147/JMDH.S284707

52. Defar A, Molla G, Abdella S, et al. Knowledge, practice and associated factors towards the prevention of COVID-19 among high-risk groups: a cross-sectional study in Addis Ababa, Ethiopia. PLoS One. 2021;16(3):e0248420. doi:10.1371/journal.pone.0248420
53. Lee H, Moon SJ, Ndombi GO, Kim K-N, Berhe H, Nam EW. COVID-19 perception, knowledge, and preventive practice: comparison between South Korea, Ethiopia, and Democratic Republic of Congo. Afr J Reprod Health. 2020;24(2):66-77.

54. Jose R, Narendran M, Bindu A, Beevi N, Manju L, Benny P. Public perception and preparedness for the pandemic COVID 19: a health belief model approach. Clin Epidemiol Glob Health. 2020;9:41-46. doi:10.1016/j.cegh.2020.06.009

55. Rgn AH, Rgn HEW. Role of self-efficacy and behaviour change. Int J Nurs Pract. 2021;Volume 14(2):106-115. doi:10.1046/j.1440172x.2002.00352.x

56. Schwarzer R, Fuchs R. Self-efficacy and health behaviours. In: Predicting Health Behavior: Research and Practice with Social Cognition Models. 163, 1996:196.

57. Shahnazi H, Ahmadi-Livani M, Pahlavanzadeh B, Rajabi A, Hamrah MS, Charkazi A. Assessing Preventive Health Behaviors from COVID-19 based on the Health Belief Model (HBM) among people in golestan province: a Cross-Sectional Study in Northern Iran; 2020.

58. Jones CL, Jensen JD, Scherr CL, Brown NR, Christy K, Weaver J. The health belief model as an explanatory framework in communication research: exploring parallel, serial, and moderated mediation. Health Commun. 2015;30(6):566-576. doi:10.1080/10410236.20 13.873363
Journal of Multidisciplinary Healthcare

\section{Publish your work in this journal}

The Journal of Multidisciplinary Healthcare is an international, peerreviewed open-access journal that aims to represent and publish research in healthcare areas delivered by practitioners of different disciplines. This includes studies and reviews conducted by multidisciplinary teams as well as research which evaluates the results or conduct of such teams or healthcare processes in general. The journal

\section{Dovepress}

covers a very wide range of areas and welcomes submissions from practitioners at all levels, from all over the world. The manuscript management system is completely online and includes a very quick and fair peer-review system. Visit http://www.dovepress.com/testimonials. php to read real quotes from published authors. 